\title{
The impact of casino proximity on northeast urban communities: a literature review
}

\author{
Paulette J. O'Gilvie (10) ${ }^{1 凶}$
}

Gambling legalization, regulation, and casino proliferation in the United States have increased casino-gambling participation. The three A's (accessibility, availability, and acceptability), known as ecological predictors of casino-gambling participation, have also been linked to the flood of casinos, including the influx of urban casinos in major metropolitan cities along the northeast corridor. Links between casino proximity, increased casino participation, and gambling-related problems are reported in the gambling and casino proximity literature but the relationship between casino proximity and urban casino communities have not been fully investigated in current literature. The purpose of this article is to present a comprehensive review of casino proximity and northeast urban casinos and host communities to the discussion on the construct, casino proximity and the impact on northeast urban casino communities by explaining the implications to those communities through extensive literature review. The review found that (i) urban casinos are typically placed in low socio-economic communities with some existing gambling culture, (ii) socio-economic improvement are promised to existing disadvantaged communities prior to the adoption of casinos, but modest economic benefits realized in urban casino neighborhoods are unsustainable, and (iii) increased accessibility and availability of urban casinos due to proximity could increase casino participation, which in turn could potentially increase gambling-related problems. Results of this literature review also indicated that gambling-related problems from proximity to casinos could produce negative socio-economic outcomes for host communities. Key stakeholders (including legislators, community workers, social services professionals, scholar-practitioners, and the casino-gambling industry) could benefit from this review given the increase in urban casino in major metro areas, and the potential impact those casinos can have on host and neighboring communities. Although very little is known about the impact of casino proximity on northeast corridor urban casinos in the megalopolis, even less is known about the relationship between proximity of urban casinos and their impact on host communities. Further investigation, particularly on the socio-economic outcomes for urban casino communities, is warranted.

\footnotetext{
${ }^{1}$ Capella University, Minneapolis, MN, USA. ${ }^{凶}$ email: pogilvie@capellauniversity.edu
} 


\section{Introduction}

ommercial casino gambling saw a worldwide increase from the 1990s to the mid-2000s (Hodgins and Petry, 2016; Shaffer et al., 2006). Yet, the United States was slow to legalize gambling, especially in the northeast where only Atlantic City, a mini Las Vegas with mid-to low-end destination casinos, and one tribal casino, Foxwoods, run by the Pequot Indians in Mashantucket, Connecticut, existed. However, when state governments determined that several forms of legalized gambling such as horseracing, lotteries, and casinos could provide additional revenues, a push for gambling legalization increased (Tidwell et al., 2015; Walker and Jackson, 2011), and consequently, more gambling outlets, especially casinos, were authorized and opened. By 2000, 48 states had authorized legal gambling (Petry and Blanco, 2013), with more than 350 casinos operating in 29 states (Wenz, 2014, p. 137).

Gambling legalization continued to increase casino regulation such that casino proliferation expanded across the country (Institute for American Values [IAV, 2013]; Martin et al., 2011; Stansbury et al., 2015; Tolchard, 2015; Tong and Chim, 2013; Welte et al., 2016a; Welte et al., 2016b), including authorization for more casinos in the northeast (Conway, 2015). Connecticut opened Mohegan Sun Casino in 1996, a second tribal operation in Uncasville, while New York and Pennsylvania opened commercial casinos in 2004, and Maryland followed in 2010 (Nower, Volberg, and Caler, 2017; Tidwell et al., 2015). At year-end 2018, the American Gaming Association ([AGA], 2019) reported a record number of 979 casinos, which included 465 commercial casinos (land-based, riverboats, and racinos) and 514 tribal casinos across 43 locations in the country.

The emergence of urban casinos, another type of casino-gambling outlet began to re-shape the ecological landscape of major metropolitan cities in the early 2000s. Some of the urban casinos in the northeast are also racetrack casinos or racinos (American Casino Guide, n.d.; American Gaming Association ([AGA], 2018; Conway, 2015; Welte et al., 2016a; Welte et al., 2016b), which are extensions of existing racetracks. Many racinos only operate slot machines known as video lottery terminals (VLTs) (AGA, 2019; Kelly and Catania, 2014; Welte et al., 2016a; Welte et al., 2016b). However, this newer type of casino gambling is a deviation from traditional casinogambling operations that generally offer slot machines and a variety of table games with live dealers.

Despite limited gaming options, major northeast Metropolitan Statistical Areas (MSAs) or metro areas (United States Department of Agriculture Economic Research Center [USDA ERC], n.d.) have adopted casinos and racinos (Conway, 2015). In the Northeast megalopolis that consists of major metropolitan cities along the corridor between Boston and Washington, D.C., (Coe et al., 2018), urban casinos are concentrated in three major cities: New York City, Philadelphia, and Baltimore. All northeast corridor casinos are commercial casinos, but only New York City and Philadelphia operate racinos.

Before introducing northeast metro area casinos, casino participation and gambling were mainly conducted at the Mohegan Sun and Foxwoods casinos in Connecticut, and the Atlantic City casinos in New Jersey. Legalization continued to pave the way for more casinos, including the new wave of urban casinos, which sometimes joined existing racetracks. Casino-gambling participation increased with urban casinos becoming more accessible, available, and acceptable (Conway, 2015; Tolchard, 2015).

Research studies that explored casino accessibility and availability in the context of casino proximity found an association between the constructs (accessibility and availability) and problem gambling or other gambling-related problems (Ariyabuddhiphongs, 2012; Conway, 2015; Martin et al., 2011; Tolchard, 2015; Tse et al., 2012; Welte et al., 2016a; Welte et al., 2016b). Several researchers
(Philander, 2019; Welte et al., 2017; Welte et al., 2016a; Welte et al., 2016b; Welte et al., 2004; Xouridas et al., 2016), who have studied casino proximity have also reported that this construct could increase the likelihood of gambling participation based on the measure of proximity. While many of those studies occurred before the influx of casinos in major northeast cities, accessibility and availability, or the convenience of urban casinos could create potential gambling problems, such as economic distress, mental disorders, and health problems (Ariyabuddhiphongs, 2012; Conway, 2015; Martin et al., 2011; Stansbury et al., 2015; Tolchard, 2015; Tong and Chim, 2013) for casino patrons and the broader community. However, the construct casino proximity has not been thoroughly evaluated in an urban casino study.

Studies on casino proximity and casino expansion have not kept pace with the changes to the overall casino industry, particularly, urban casinos found in major metro areas (Conway, 2015). Previous casino studies indicated that urban casinos are placed in communities that already have a culture of gambling (Barnes et al., 2013; Redmond, 2015; Welte et al., 2016b), and, individuals who resided within close proximity to casinos were mostly likely to be problem gamblers (Moore et al., 2011). Therefore, the need to understand casino proximity as it relates to urban casino communities derives from lack of literature since socio-economic problems could potentially increase in already distressed communities due to the proximity of urban casinos; resulting in an increase in the services and interventions provided by social services professionals, and other stakeholders (legislators and community workers).

\section{Methods}

McEwan (2018) posits that a quality literature review should provide a rationale for investigating a phenomenon, include a theoretical position, and discuss and synthesize findings from existing studies. Since urban casinos in the northeast are still a relatively new phenomenon (Conway, 2015) and there is a dearth of studies in the literature, this literature review seeks to review, examine, and provide a more comprehensive understanding of the relationship between casino proximity and urban casino communities in three major cities along the northeast megalopolis corridor. Underpinned with the perspectives of exposure and adaptation theories (LaPlante and Shaffer, 2007; Philander, 2019), existing literature were synthesized and discussed to warrant this investigation.

This review utilized the four steps (identification, screening, eligibility, and inclusion) in the Preferred Reporting Items for Systematic Reviews and Meta-Analysis (PRISMA) protocol were adopted (Browning and Rigolon, 2019) using hand-searching in Academic Search Premier, ProQuest Central, Google Scholar, PsychINFO, and SocINDEX databases. Multiple search terms, including casino proximity, casino accessibility, casino location, casino communities, urban gambling, urban casino, casino proximity and socio-economic status, casino proximity and problem gambling, and northeast casinos, and several different combinations of the preceding terms were used to locate scholarly articles and studies that covered or referenced the search terms.

Date restrictions were minimal but to achieve substantive contributions to the casino proximity and urban casino literature, articles with a date range from 2004 to 2019 identified 210 articles, which met one or more of the search terms. However, several articles that met the date requirement, and contained the construct, casino proximity, had associations to problem gambling, pathological gambling, gambling in older adults, and cooccurring disorders; thus, those articles were not selected, excluding 111 from the 210 articles identified. 
The titles and abstracts of the remaining 99 articles were screened, and this resulted in the exclusion of an additional 26 articles. Eligibility of the remaining 73 articles for this review was based on article relevance, authority, and currency (Browning and Rigolon, 2019) for the inclusion criteria. While relevance delineated the applicability of each article for the present review, authority vetted each article to determine academic applicability and peer-reviewed standards. To evaluate currency, Google Scholar was the primary source used to determine the number of citations for each article reviewed (Mensah, 2019). Since reading the full text for each article was part of the eligibility process, an additional 18 articles were found to be ineligible. Thus, 55 articles met the criteria for final inclusion in this literature review.

\section{Results from the literature}

This review presents relevant literature supporting the topic, the impact of casino proximity on northeast urban casino communities. Literature to support the contextual constructs appropriate to the research topic is presented and separated into three major areas: (i) historical overview of gambling including an overview of casino gambling and major northeast gambling outlets, (ii) constructs of casino proximity, and (iii) theoretical underpinnings of exposure and adaptation frameworks within the casino-gambling literature. Gambling disorder, which is relevant in casino proximity studies, is briefly presented as a fourth area in this review.

Historical overview of gambling. As far back as 4000 BC, gambling has been used as a form of wager (Ferentzy and Turner, 2012). Shaffer et al. (2006) referred to gambling as "different games of chance" that had restricted access by "geography and legal status" (p. 427). In most states where gambling is legal, an activity is defined as gambling if it meets all three of the following criteria: "(a) something of value wagered and at-risk (consideration), (b) the opportunity to receive something of value in return (reward or prize), and (c) the element of chance" (Tidwell et al., 2015, p. 14).

Tidwell, Welte, Barnes, and Dayanim (2015) identified 24 types of legalized gambling ranging from state-run lotteries and staterun keno-style games to casinos (destination, Indian-run, parimutuel), to racetracks, and online gambling:

State-run lotteries and state-run keno-style games; four types of charitable gaming (bingo, raffles, pull-tabs, and other charitable gaming, such as Casino or Las Vegas Nights); various forms of pari-mutuel wagering (horse racing, dog racing, simulcast racing, off-track betting, jai alai, instant/historical horse racing, and advance deposit wagering); three types of non-Indian casino-style gambling (commercial or state-run casinos, riverboat or cruise ships, and racinos); two forms of Indian gaming (tribal bingo parlors and tribal casinos); cardrooms; social gambling; sports betting; Calcutta pool; video or electronic gaming machines; and online gambling (p. 14).

The District of Columbia and every state participate in at least two types of gambling. Utah and Hawaii are the exception and engages in one kind of gambling each (Welte et al., 2016b).

Nevertheless, gambling was not always an appealing activity and predominately associated with individuals from lower socioeconomic backgrounds (Braverman and Shaffer, 2012; Tolchard, 2015). To this end, several states banned gambling in the early 1990s, including Nevada's anti-gambling legislation in 1910 (Petry and Blanco, 2013). Yet, as a way to generate income following the Great Depression, the State of Nevada opened the first on-land casino in 1931 (Tidwell et al., 2015). Forty-six years later, in 1978, the Resorts Casino opened in Atlantic City. Since then, legalization and regulation, proliferation of casinos, and new modes of gambling have evolved, including South Dakota's "small-stakes casinos" in 1989 (Wenz, 2014, p. 137), and Iowa riverboat casinos in 1991 (Wenz, 2014). Colorado also began to operate casinos in 1991, followed by Mississippi in 1992, Louisiana in 1993, and Michigan in 1999 (Nower et al., 2017; Tidwell et al., 2015).

At the turn of the twenty-first century, new and additional modes of gambling were on the rise. Online or Internet casino gambling was first to emerge, followed by sports betting (Nower et al., 2017). Although online gambling saw an upward trend from 1999 to 2011, online gambling was not authorized by any state until 2012, when Delaware was permitted to offer online casino gambling. Nevada and New Jersey subsequently began online casino gambling in 2013 (Nower et al., 2017). With this additional mode of casino gambling, Gainsbury et al. (2012) indicated that while online gamblers also tend to participate in on-land gambling, Nower et al. (2017) posited that these higher gambling activities were difficult to assess. Nower et al. (2017) asserts that it is not known whether online gambling is a substitute for on-land gambling or just another mode of gambling without further research. Hodgins and Petry (2016) also noted that online gambling accounts for a small percentage of the overall commercial gambling revenue despite increases in that mode of gambling.

On the other hand, legal sports betting, which was previously "confined to Nevada" (AGA, 2019, p. 32), expanded to seven more states at year-end 2018. Commercial casinos in four northeast states (Delaware, New Jersey, Pennsylvania, and Rhode Island), Mississippi, and West Virginia gained approval to offer sports betting on property. However, only Nevada, New Jersey, and West Virginia offer mobile and online sports betting statewide in addition to on-property sports betting at commercial casinos. Mississippi also offers sports betting in tribal casinos, and New Mexico became the eighth state to offer on-property sports betting in that state's tribal casinos in October 2018 (AGA, 2019, p. 14).

The increase in casinos across the country resulted in entertainment rivalry as casinos entertainment started to attract adults. Hence, gambling revenues especially casino-gambling revenues surpassed theme parks and movie theatres and moved casino gambling into the mainstream of American entertainment (Conway, 2015; Kerber et al., 2015; Martin et al., 2011; Stansbury et al., 2015; Thompson and McNeilly, 2016; Tse et al., 2012). Despite this growth, casino-gambling tax revenues are not the same across all states. The number and types of gambling outlets and the state's geographic location determine gambling tax revenues.

For instance, New York's gambling tax revenue did not include any commercial casino taxes for the 2004 reporting period, yet the state ranked highest in total gambling tax revenue at \$1.995 billion (Walker and Jackson, 2011). Illinois ranked second at $\$ 1.355$ billion, while New Jersey ranked third at $\$ 1.266$ billion. In contrast, Nevada ranked the highest in commercial casino tax revenues for the same period reporting $\$ 887$ million, and New Jersey followed in second place with $\$ 470$ million in commercial casino taxes (Walker and Jackson, 2011). The reported commercial casino tax revenues for both Nevada and New Jersey were consistent with established destination casino-gambling outlets in the U.S.

As a consequence, legalization and casino expansion successfully contributed to the steady growth in casino revenues between 2009 and 2014 until revenues saw a decline from 2014 to 2015 (AGA, 2019). However, at year-end 2018, the AGA (2019), reported that the U.S. casino industry saw its highest revenues of $\$ 41.68$ billion from consumer spending, a 3.5 percent increase 
from 2017 (p.6). Significant contributors to the rise in casino revenues include urban-area casinos in three major metropolitan cities (New York City, Philadelphia, and Baltimore). Standalone northeast urban casinos in the megalopolis reported revenues that ranked in the top ten commercial casino-gambling revenues outside of Nevada. Undoubtedly, accessibility and availability of casinos have had a significant effect on commercial casino revenues.

The Resorts World Casino New York City (RWCNYC), an urban racino in the New York metro area, reported the highest commercial casino gaming revenue at $\$ 852$ million in 2018 for a standalone casino outside of Nevada (AGA, 2019). RWCNYC, located just 14 miles from metropolitan New York City, held onto its 2017 first place. The urban and destination casino MGM National Harbor (MGM), which sits between Baltimore and Washington, D.C., reported just above $\$ 700$ million in gaming revenues in third place. At the same time, Parx Casino and Racing (Parx), just outside of Philadelphia, ranked fifth with approximately $\$ 600$ million. Live Casino and Hotel (within proximity to the Baltimore metro area) ranked eighth with reported gaming revenues slightly below $\$ 600$ million (AGA, 2019, p. 86). Given the positive economic benefits for the casinos and their respective state governments, urban casinos in the northeast have made considerable contributions to host states and the overall U.S. commercial casino revenues. However, it is unclear how these economic benefits translate into positive outcomes for the local host urban communities.

Casino-gambling overview. The prominent Las Vegas Strip of high-end casino resort hotels where food, entertainment, and gambling are always in abundant supply has been a steady factor in commercial casino revenues. As the primary destination for adult gambling and entertainment in the U.S., Las Vegas, the first legal hub for gambling (Tidwell et al., 2015; Wenz, 2014), has been the number one commercial casino market for years generating and reporting the highest commercial casino revenues (AGA, 2019). In 2018, the Las Vegas Strip reported gaming revenues of $\$ 6.59$ billion with the Atlantic City market in second place at $\$ 2.51$ billion. The Chicago gambling market with established casinos ranked third with $\$ 1.95$ billion. In contrast, two relatively new northeast commercial casino markets, Baltimore-Washington, D.C., and New York City, ranked fourth and fifth with revenues of $\$ 1.88$ billion and $\$ 1.45$ billion, respectively (AGA, 2019, p. 18). The Philadelphia casino market ranked seventh with reported revenues of $\$ 1.30$ billion, while the Connecticut market did not make the list of top 20 commercial casino markets.

Before nationwide gambling legalization, overall gambling, and in particular casino gambling, was not always an acceptable activity since gambling activities had connotations to organized crime (Tolchard, 2015). However, this perception started to shift with legalization and regulation (Petry and Blanco, 2013), which helped to change casino gambling into a socially acceptable activity for adults (Ashley and Boehlke, 2012). Findings from a 2019 AGA commissioned study indicated that $49 \%$ of American adults saw the casino-gambling industry as acceptable. This was the highest rate of acceptability recorded by the AGA for the casino gaming industry and represented a 4-percent increase from 2018.

An examination of the literature revealed that gambling and casino participation had increased due to accessibility, availability, and acceptability - the three As-of gambling establishments (Ashley and Boehlke, 2012; Conway, 2105; Shaffer et al., 2006). The ecological predictors or three As (Conway, 2015; Tanner and Mazmanian, 2016; Tolchard, 2015) create additional opportunities for casino gambling, and when opportunities for casino gambling exist; the risk for gambling-related problems could likely increase (Conway, 2015; Martin et al., 2011; Philander, 2019; Tolchard, 2015; Tong and Chim, 2013). Gambling-related problems such as economic distress, mental disorders, and health problems, could potentially increase from increased gambling participation. However, gambling-related problems have not been explicitly correlated to the proximity of urban casinos.

Research studies that focus on urban casinos and urban casinogambling-related problems are limited (Conway, 2015; Tolchard, 2015). There is even less research on the impact of urban casinos of socio-economic levels in host communities. Furthermore, Hodgins and Petry (2016) posited that although overall gambling research had increased, limited funds (Blaszczynski, 2011), discrepancies between government, various stakeholders, and academic researchers, remain barriers extending gambling research. Hence, this literature review is poised to advance urban casino-gambling literature.

Major northeast casino-gambling outlets. For more than a decade, the U.S. observed an influx of urban casinos. As more cities began to adopt casinos, opportunities for casino gambling moved closer to major metropolitan areas; hence, closer to homes and workplaces of casino patrons (Conway, 2015; Hing and Nisbet, 2010; Tong and Chim, 2013; Welte et al., 2016a; Welte et al., 2016b). Legalized gambling, casino proliferation, and social acceptability of casino gambling in the U.S. have created more opportunities for casino participation in urban areas, such that casinos are available to adults for entertainment and socialization (Ashley and Boehlke, 2012; Conway, 2015; Martin et al., 2011; Moore et al., 2011; Petry and Blanco, 2013; Stansbury et al., 2015; Thomas et al., 2011; Tolchard, 2015). However, urban casinos, as the newest type of on-land casinos, have not been fully explored in the literature (Conway, 2015).

Commercial casinos in the northeast currently include resortstyle destination casinos and racinos. Resort-style casinos are also known as destination casinos because they are in destinations or major casino markets such as Atlantic City, Connecticut, and Las Vegas. Hence, destination casinos offer full-service amenities: hotel accommodations, spas, dining options, entertainment options, and several gaming options, including live dealers (American Casino Guide, n.d.; Economopoulos, 2015). Some resort-style casinos like the tribal Mohegan Sun and Foxwoods casinos are not classified as commercial casinos even though they provide full-scale amenities. However, only a few destination casinos are reasonably close to major metropolitan cities; many are generally found in rural or suburban areas. The MGM on Maryland's National Harbor was the first destination resort-style casino to open on the northeast corridor and sits within proximity, approximately 14 miles (Google Maps, n.d.) of the Washington, D.C. metro area.

Initially, commercial casinos such as racinos were opened in rural or suburban areas (Conway, 2015; Tolchard, 2015); but since the mid-2000s, several of the urban casinos or racinos found along the northeast corridor were opened in New York City, Philadelphia, and Baltimore (American Casino Guide, n.d.; Conway, 2015). Since racinos are a hybrid of a racetrack and a casino (Kelly and Catania, 2014; Welte et al., 2016a; Welte et al., 2016b), these gambling outlets are injected into environments that already have an existing culture of gambling (Barnes et al., 2013; Redmond, 2015; Welte et al., 2016b), or where individuals are likely to be vulnerable to problem gambling (Conway, 2015; Welte et al., 2016b). However, as a new phenomenon, little research is reported that examines problem gambling in relation to the proximity of urban casinos (Conway, 2015). 
Northeast corridor urban casinos. Although New York and Pennsylvania were permitted to operate casinos in 2004 (Tidwell et al., 2015), the Philadelphia metro area surpassed New York City with three urban casinos: Harrahs Philadelphia Casino and Racetrack, and Parx, and Sugarhouse Casino, which opened in 2007 and 2010, respectively (Conway, 2015). It would take Maryland six more years to obtain permits and licenses to operate casinos (Tidwell et al., 2015). Still, the Baltimore metro area did not host its first urban-area casino until 2012, when Live Casino (Live) opened. Two years later, Baltimore City opened the Horseshoe Casino Baltimore (Horseshoe) in August 2014.

In between the metro Philadelphia and Baltimore casinos, New York City opened its first urban casino and racino, the RWCNYC, in October 2011. Within less than a year of operation, RWCNYC's slot revenue had surpassed the tribal casinos and the land-based destination casinos in Connecticut and Atlantic City, respectively (Bagli, 2012). RWCNYC received considerable media coverage in the mainstream news media, ranging from The New York Times and the New York Daily News to other local and regional media outlets. RWCNYC also outranked Philadelphia's three urban casinos (Conway, 2015) and the Live in the Baltimore metro area. Another racino, the Empire City Casino (Empire City), previously opened in 2007 in Yonkers, New York, has easy access to/from New York City (Google Maps, n.d.), although Yonkers is not considered part of metropolitan New York City, Empire City was also outranked. Neither the Connecticut shoreline nor the Boston metro area hosts urban casinos.

Racinos, unlike destination casinos, are not a new form of gambling, but racinos operating in major urban cities, particularly in northeastern metropolitan cities, are a new phenomenon (Conway, 2015). For example, New York State's Fingerlakes Gaming and Racetrack in Farmington, and Batavia Downs Casino in Batavia, were traditional racetracks that were rebranded when casinos were added 2004 and 2005 respectively (Kelly and Catania, 2014). The RWCNYC in metropolitan New York and Empire City in Yonkers, New York, are extensions of existing racetracks with a culture of racetrack gambling. The RWCNYC and Empire City's proximities and ease of access from New York metro area, 15 to $20 \mathrm{~min}$ drive or 45 -min ride on public transportation (Google Maps, n.d.), from mid-town Manhattan, could eliminate the two-hour drive to Atlantic City or Connecticut's Foxwoods or Mohegan Sun casinos.

Similarly, close to the Philadelphia metro area, Parx, which initially opened as the Keystone Racetrack in 1974, went through several transitions before Parx officially opened in December 2010 (Conway, 2015), as a commercial casino. Harrahs Philadelphia Casino and Racetrack in Chester, approximately 14.5 miles from Philadelphia's 30th Street Station (Google Maps, n.d.), also began as a racino in 2007, but in 2010 live table games were permitted (Conway, 2015; Parmley, 2010). Sugarhouse Casino, now called Rivers Casino Philadelphia, is an urban standalone commercial casino without a racetrack in the Philadelphia metro area.

On the other hand, the Baltimore metro area does not host any racinos. Still, in December 2016, the MGM graced the Maryland National Harbor skyline and joined the ranks as both an urban casino and a resort-style destination casino. The MGM was the first northeast urban resort-style casino to open within proximity, approximately 14 miles from the Washington D.C. metro area (Google Maps, n.d.) to a major MSA. Baltimore metro also hosts the Horseshoe, an urban casino located in downtown Baltimore, approximately 13 miles from the Live in Hanover, which is only five miles from the BWI Amtrak Rail Station. Although neither the Live nor the Horseshoe has a racetrack, they are within a 10 to 15-mile radius, respectively, of the Laurel Racetrack (Google Maps, n.d.), which has had a mode of horseracing since 1911.
Overall, racinos provide more gambling opportunities based on their well-established gambling culture of racetrack betting. Still, there is a lack of research on urban casinos, albeit racinos or not. There is even less research, on how the proximity of northeast urban casinos impacts their host communities.

On the whole, gambling legalization and regulation helped to change gambling perceptions, such that legal gambling activities were seen more favorably (Ashley and Boehlke, 2012; Petry and Blanco, 2013). Lottery and scratch-off tickets, which were borne out of legalization, are still readily available in many local establishments as a part of daily activities for many American adults (Petry and Blanco, 2013). The influx of casinos including the new mode of urban casino gambling (Conway, 2015) are factors that also helped to move overall casino gambling into the mainstream of America entertainment (Martin et al., 2011; Stansbury et al., 2015; Thompson and McNeilly, 2016; Tse et al., 2012).

Urban casino gambling is even more accessible, available, and acceptable in the northeast; yet, the risks of increased urban casino-gambling participation, which could potentially impact the prevalence of gambling-related problems such as economic distress, mental disorders, and health problems (Ariyabuddhiphongs, 2012; Conway, 2015; Martin et al., 2011; Stansbury et al., 2015; Tolchard, 2015; Tong and Chim, 2013; Turner et al., 2018) for casino patrons and the community-atlarge have not been exhausted in the literature. Hardly any research on urban casinos and how they impact host environments in major metropolitan cities were uncovered. Therefore, this article extends the understanding of northeast corridor urban casino gambling.

Casino proximity. A review of the broader literature revealed no clear definition of casino proximity. Griswold and Nichols (2006) found that when casino proximity was defined greater than 15 miles from an MSA, the variable (casino proximity) size decreased and became statistically insignificant (p. 390). Similarly, the time/distance that an individual or a population used/traveled to get to a casino were also used in studies that defined casino accessibility and casino proximity (Conway, 2015; Robitaille and Herjean, 2008). Some literature defined casino proximity as "the physical distance or driving distance between [participant's] residing home and nearest casino" (Tong and Chim, 2013, p. 4; Welte et al., 2004), whereas other studies indicated that distance from casino gambling venues and individuals' homes vary by researchers' definitions of casino proximity (LaPlante and Shaffer, 2007; Tong and Chim, 2013).

One nationally conducted study for the National Gambling Impact Study Commission reported that casinos located within 50 miles from individuals' homes contributed to gambling-related problems (Gerstein et al., 1999, p. 10; Welte et al., 2016a, p. 2). An earlier study reported that 10 miles from individual homes indicated a likelihood of gambling-related problems (Welte et al., 2004). Tong and Chim (2013) also found that the lack of a standard definition, measurement, or tool to define casino proximity, resulted in the terms high and low casino proximity that varied across the studies analyzed in their systematic review. However, those studies occurred before the vast influx of urban casinos or racinos (Tong and Chim, 2013; Welte et al., 2016a; Welte et al., 2016b), and specifically focused on rural or destination casinos in the analyses.

Conway's (2015) Philadelphia urban casino proximity case study used vulnerability modeling to focus on the vulnerability of problem gambling in commercial casinos in Philadelphia. A Geographic Information System (GIS) vulnerability model was developed to determine access based on the measure of proximity 
to casinos by those individuals who were most vulnerable to problem gambling. The study was limited to the use of secondary data even though the findings indicated that the three Philadelphia urban casinos were located in areas where individuals were vulnerable to problem gambling. As the first known study to report on one aspect of urban casino gambling in the largest metropolitan city in the megalopolis, the study provided a framework for examining problem gambling vulnerability in urban casino communities in Philadelphia. Conway (2015) asserted that the spread of casinos to large metropolitan cities was a deviation from the past when casinos were located in small to mid-sized towns; hence, gaps in the literature on geographic research (p. 21).

Proximity to casinos was also investigated in a qualitative gambling study where the researchers (Thomas et al., 2011) reported that individuals who resided closer to casinos were most likely to be problem gamblers. As one of the correlates of casino proximity, accessibility was regarded as multidimensional even though Thomas et al. (2011) posited, "it is still poorly understood" (p. 88). These results indicated that reliance on gambling establishments such as casinos could potentially lead to problem gambling. However, participants in the study saw gambling as a safe social activity.

There is some evidence in the literature that frequent gambling in casinos could increase the risk of gambling-related problems such as problem gambling or gambling disorder (Ariyabuddhiphongs, 2012; Conway, 2015; Philander, 2019; Stansbury et al., 2015; Tolchard, 2015; Tong and Chim, 2013). Several authors have also reported that casino proximity could increase the likelihood of gambling participation based on the measure of proximity (Philander, 2019; Welte et al., 2017; Welte et al., 2016a, 2016b; Welte et al., 2004; Xouridas et al., 2016). However, the construct casino proximity has not been extensively evaluated in an urban casino study.

Exposure and adaptation theories. Two ecological constructs of casino proximity (accessibility and availability) were investigated with the perspectives of exposure theory framework (LaPlante and Shaffer, 2007), and linkages between casino proximity and problem gambling were found. Under the exposure theory framework, Shaffer et al. (2004) referred to casinos as a toxin, which, when placed into the environment could result in infections such as gambling-related problems. Other researchers (Conway, 2015; Welte et al., 2017; Welte et al., 2016a; Welte et al., 2016b; Welte et al., 2004; Xouridas et al., 2016) investigated casino proximity and also reported that accessibility and availability as constructs were linked to gambling-related problems such as problem gambling. Though limited, literature in the field further indicated a higher prevalence of problem gambling due to casino accessibility and casino proximity (Ariyabuddhiphongs, 2012; Barnes et al., 2013; Conway, 2015; Tong and Chim, 2013; Welte et al., 2016a; Welte et al., 2016b).

The earliest account of exposure theory in the gambling literature dates back to Shaffer, LaBrie, and LaPlante's (2004) article, which sought to define the regional exposure model (REM) that would quantify gambling research during its developing stage as a new topic of study. According to Shaffer et al. (2004), exposure theory posits that environmental toxins could increase the likelihood of diseases related to such toxins. Gambling-related problems, the researchers found could impact the health and well being of communities and society as a whole from exposure to environmental toxins, such as casinos (LaPlante and Shaffer, 2007; Philander, 2019).

The REM was therefore designed to examine various social phenomena, in particular, gambling, by linking physical accessibility to gambling establishments and individuals' responses to such exposures (Shaffer et al., 2004; Vasiliadis et al., 2013). Further, Shaffer et al. (2004) also explained that in addition to environmental factors, various social settings could also influence and contribute to gambling participation that could have an adverse effect on individuals and communities. Examples include the proximity of gambling establishments to gambling patrons' communities and neighborhoods, and being employed by a casino or other gambling establishment could potentially increase levels of toxicity or infection brought about by exposure to gambling (Shaffer et al., 2004; Vasiliadis et al., 2013). Prentice and Zeng (2018) also cited gambling advertising as a factor in gambling participation.

Adaptation theory. Although adaptation theory complements exposure theory, it also competes with its counterpart. Introduced into the gambling literature just over a decade ago (Prentice and Zeng, 2018), adaptation theory suggests that resistance to toxins and adaptation could occur over time. A concept referred to as the "adaptation effect," which accounts for adjustments in "mature gambling markets" (Hodgins and Petry, 2016, p. 1517; Shaffer, 2005). Prentice and Zeng (2018) posited that those individuals, who were exposed to new environmental toxins could over time, adapt, especially as the market reached saturation.

Accordingly, adaptation theory proposes that after the initial increase in adverse reactions (gambling-related problems) from exposure to those new environmental toxins (casinos), symptoms subsequently decrease as adaptation and resistance to the toxins are achieved (LaPlante and Shaffer, 2007) over time (Hodgins and Petry, 2016; Prentice and Zeng, 2018). Welte et al. (2017), in an earlier study, explained that individuals who live in mature gambling communities (such as Las Vegas and Atlantic City) for more than ten years gamble less than those who do not. This hypothesis has been postulated for destination casinos in mature gambling communities (Hodgins and Petry, 2016; Shaffer, 2005); however, urban casino communities have not been empirically tested using the perspectives of adaptation theory due to the newness of this phenomenon.

Increased exposure to the toxins (casinos) does not necessarily lead to an increase in gambling participation even though the initial contact with the toxins (casinos) could result in infection (LaPlante and Shaffer, 2007; Prentice and Zeng, 2018; Shaffer et al., 2004). However, several studies (Welte et al., 2017; Welte et al., 2016a; Welte et al., 2016b; Welte et al., 2004; Xouridas et al., 2016) have also reported that casino proximity could increase the likelihood of gambling participation based on the measure of proximity. On the contrary, Prentice and Zeng (2018) established that conclusive relationships between gambling exposure and problems associated with increased exposure had not been reported.

The dual framework of exposure and adaptation theories reported limited application in empirical studies or studies with primary data (Shaffer et al., 2004; Welte et al., 2016a; Welte et al., 2016b). While exposure theory perspectives have been used in limited casino proximity and other gambling studies, fewer studies used adaptation theory perspectives (Prentice and Zeng, 2018; Welte et al., 2016a, 2016b). Recently, the aspects of adaptation theory reported minimal application in the casino and gambling literature with empirical data (Philander, 2019).

Philander (2019) examined the regional impacts of casino availability on gambling participation and the development of gambling-related problems. Philander (2019) found that both gambling participation and problem gambling risk increased after increased exposure to casinos. Focusing the study with exposure and adaptation theories perspectives, the study's large sample $(n=50,048)$ covered four Canadian provinces and tested the perspectives of each theory. Based on the results, Philander (2019) 
reported that the "empirical findings provide evidence for exposure and adaptation forces as described by LaPlante and Shaffer (2007)" (p. 176). However, the large sample size posed limitations such as generalizability for other future studies.

Gambling disorder. Gambling disorder and its apparent relationship to casino proximity warranted discussion in this literature review. Gambling disorder, previously termed pathological gambling was renamed to gambling disorder and reclassified from an impulse control disorder to the category of "Substance-related and Addictive Disorders" in the Diagnostic and Statistical Manual of Mental Disorders-Fifth Edition ([DSM-5], American Psychiatric Association, 2013; Hodgins and Petry, 2016; Rash and Petry, 2016; Stinchfield et al., 2016; Temcheff et al., 2016).

Problem gambling is defined as the second most severe form of disordered gambling (Diagnostic and Statistical Manual of Mental Disorders-Fourth Edition, Text Revision ([DSM-IV-TR], American Psychiatric Association, 2000). Problem gambling is typically associated with activities such as participating in more than one type of gambling activity and over-spending monies intended for other purposes (Barnes et al., 2015). Since participating in any kind or mode of gambling could potentially increase the prevalence of gambling-related problems, both gambling disorder and problem gambling are essential constructs in casino and gambling research studies.

Gambling disorder and problem gambling are frequently used interchangeably in the gambling literature; however, studies that examined casinos, casino participation, and socio-economic aspects of casino gambling, commonly used problem gambling (Ashley and Boehlke, 2012; Barnes et al., 2013; Baxter et al., 2016; Conway, 2015; Gattis and Cunningham-Williams, 2011; Hodgins and Petry, 2016; Stansbury et al., 2015; Tong and Chim, 2013; Turner et al., 2018; Welte et al., 2016a; Welte et al., 2016b).

Overall, gambling-related problems that lead to problem gambling or gambling disorder are undisguised, undetected, and uncovered until the difficulties have exacerbated. Adult gamblers who face gambling-related problems suffer lack of detection, or, they conceal such problems due to embarrassment, shame, guilt, and lack knowledge of where to seek help (Baxter et al., 2016; Kerber et al., 2015; Martin et al., 2011, Stansbury et al., 2015). Gambling-related problems could also result in increased social services intervention, prevention, and treatment (Gattis and Cunningham-Williams, 2011; Stansbury et al., 2015; Walker and Sobel, 2016). However, social services professionals, without the requisite training, are unable to discover signs of gambling-related problems due to the lack of gambling studies (Hodgins and Petry, 2016; Thompson and McNeilly, 2016) and gambling education (Engels et al., 2013).

\section{Discussion}

The proximity of casinos to urban communities in major metropolitan areas including New York City, Baltimore, and Philadelphia has gained traction due to accessibility, availability, and acceptability, or the three As, and ecological predictors of urban casino gambling (Ariyabuddhiphongs, 2012; Conway, 2015; Tolchard, 2015). Yet, those ecological predictors have not been fully explored in an urban casino proximity study in the northeast. When casino proximity and gambling-related problems such as problem gambling were examined in the context of casino accessibility and casino availability, an association was reported (Ariyabuddhiphongs, 2012; Conway, 2015; Martin et al., 2011; Tolchard, 2015; Tse et al., 2012; Turner et al., 2018; Welte et al., 2016a; Welte et al., 2016b). Accessibility and availability are two significant ecological factors that could impact urban casinogambling participation based on proximity to urban casinos
(Conway, 2015; Tolchard, 2015). Furthermore, accessibility and availability of urban casinos, when coupled with the acceptability of casino gambling, could alleviate the need to travel out of town for casino-gambling participation.

State governments continue to realize substantive tax revenues from gambling legalization and regulation (Petry and Blanco, 2013). Still, it is unclear how revenues from casino gambling in major northeast urban cities trickle back to the local communities. Researchers (Griswold and Nichols, 2006; Philander, 2019; Tolchard, 2015; Tong and Chim, 2013) explained that casinos could positively impact the socio-economic levels in communities with employment, sponsorship of local events, and redevelopment. Walker and Sobel (2016) posited that those positive socioeconomic benefits could occur over time, and Lim and Zhang (2017) asserted that such realized gains are unsustainable.

Conversely, casinos could also contribute to the introduction of crime, creation of undesirable businesses (such as pawnshops, payday loans, and check cashing stores), and production of problem gambling (Conway, 2015; Tolchard, 2015; Tong and Chim, 2013). Therefore, despite potential positive socio-economic benefits to host economies, casinos could negatively affect host urban cities. As urban casinos continue to increase in northeast corridor metropolitan cities, changes to the ecological landscape of those urban communities will require a deeper understanding of how urban casinos impact the overall socio-economic status of these communities, including the risks and benefits of urban casinos as a relatively new phenomenon.

Additionally, several researchers (Barnes et al., 2013; Conway, 2015; Goss et al., 2009; Redmond, 2015; Welte et al., 2016a; Welte et al., 2016b) noted that poor and disadvantaged lower socioeconomic communities have more gambling outlets than economically advantaged neighborhoods and that most urban casinos are placed in areas that already have a culture of gambling. Since many urban casinos are also racinos, at least two types of gambling (racetrack and casino) are offered. Northeast urban racinos only operate VLT slot machines as well as electronic table games such as roulette and blackjack; hence, live dealers are not permitted. Without access to live dealers to foster a level of social interaction, slot machine playing could be potentially isolating. Besides, slot machine playing is the most addictive form of casino gambling (Welte et al., 2009). Therefore, exposure to casinos in areas embedded in gambling could potentially increase gamblingrelated problems.

While the perspectives of exposure theory have been used to focus casino proximity studies, the adaptation theory perspectives (LaPlante and Shaffer, 2007; Prentice and Zeng, 2018) have not been empirically tested in casino proximity or casino-gambling studies. No studies found the use of both theories concurrently. Given the ecological factors (accessibility, availability, and acceptability) that affect casino participation, the adoption of casinos in major urban cities, and the socio-economic impact as a result of increased ecological factors, the theories of exposure and adaption were well-suited to discuss the impact of casino proximity on urban casino communities in the northeast.

This literature review provides practical implications for all stakeholders and illustrates the association between casino proximity and increased casino participation for three ecological predictors (accessibility, availability, and acceptability). Problem gambling or other gambling-related problems that have been associated with casino proximity could potentially affect socioeconomic outcomes in urban casino communities, but research is limited. Redmond (2015) suggested that as casinos increase, inequality at lower socio-economic levels would also increase. Therefore, studies to examine urban casinos and the effect those casinos have on host and neighboring communities in the major northeast cities are needed. 
Prentice and Zeng (2018) remarked that the casino business is one of the fastest-growing industries in the world. Research on casinogambling studies has not kept pace with ecological changes due to the influx of urban casinos. Urban casinos remain a new phenomenon, especially in major northeastern cities such as New York City, Philadelphia, and Baltimore (Conway, 2015). Casino proximity as a construct in urban casino research is still emerging. Although this review might be of interest to the casino gaming industry, policymakers, and social services professionals, more research focused on understanding the socio-economic implications of urban casinos due to the proximity of casinos is warranted.

\section{Data availability}

Data sharing not applicable to this article as no datasets were generated or analyzed during the current study.

Received: 13 May 2021; Accepted: 18 January 2022;

Published online: 01 February 2022

\section{References}

American Casino Guide (n.d.) New York casinos. Retrieved October 22, 2019, from https://www.americancasinoguide.com/casinos-by-state/new-york-casinos.html

American Gaming Association (2018) State of play. https://www.americangaming.org/ state-of-play/

American Gaming Association (2019) American attitudes on casino gaming 2019. https://www.americangaming.org/resources/american-attitudes-on-casinogaming-2019/

American Psychiatric Association (2000) Diagnostic and statistical manual of mental disorders (4th ed., text rev.). Author, Washington, DC

American Psychiatric Association (2013) Diagnostic and statistical manual of mental disorders (5th edn.). https://doi.org/10.1176/appi.books.9780890425596

Ariyabuddhiphongs V (2012) Older adults and gambling: a review. Int J Ment Health Addict 10(2):297-308. https://doi.org/10.1007/s11469-011-9325-6

Ashley LL, Boehlke K (2012) Pathological gambling: a general review. J Psychoactive Drugs 44(1):27-37. https://doi.org/10.1080/02791072.2012.662078

Bagli, CV (2012, October 23). Simple but local, Queens slots are hurting gambling meccas. The New York Times. https://www.nytimes.com/2012/10/24/nyregion/ aqueduct-casinos-success-may-spur-industry-expansion-in-new-york.html

Barnes GM, Welte JW, Tidwell M-CO, Hoffman JH (2013) Effect of neighborhood disadvantage on problem gambling and alcohol use. J Behav Addict 2(2):82-89. https://doi.org/10.1556/JBA.2.2013.004

Barnes GM, Welte JW, Tidwell MO, Hoffman JH (2015) Gambling and substance use: co-occurrence among adults in a recent general population study in the United States. Int Gambl Stud 15(1):55-71. https://doi.org/10.1080/ 14459795.2014.990396

Baxter A, Salmon C, Dufresne KD, Carasco-Lee A, Matheson FI(2016) Genderdifferences in felt stigma and barriers to help-seeking for problem gambling Addict Behav Rep 3:1-8. https://doi.org/10.1016/jabrep.2015.10.001

Blaszczynski A (2011) Harm minimization can be achieved by a symbiosis between government, industry, and individuals. Addiction 106(1):10-12. https:// doi.org/10.1111/j.1360-0443.2010.03231.x

Braverman J, Shaffer H (2012) How do gamblers start gambling: identifying behavioural markers for high-risk internet gambling. Eur J Public Health 22(2):273-278. https://doi.org/10.1093/eurpub/ckp232

Browning M, Rigolon A (2019) School green space and its impact on academic performance: A systematic literature review. Int J Environ Res Public Health 16(3):429. https://doi.org/10.3390/ijerph16030429

Coe J, Mahvelati S, Senior M, Asabere P (2018) Mapping NEHRP VS30 site class in Philadelphia using geophysical and existing subsurface data. Proceedings of the 11th National Conference in Earthquake Engineering, Earthquake Engineering Research Institute, Los Angeles, CA. https:// www.researchgate.net/profile/Siavash_Mahvelati/publication/ 326044660_Mapping_NEHRP_Vs30_Site_Class_in_Philadelphia_Using Geophysical_and_Existing_Subsurface_Data/links/5c715d56a6fdcc47159 5abce/Mapping-NEHRP-Vs30-Site-Class-in-Philadelphia-UsingGeophysical-and-Existing-Subsurface-Data.pdf

Conway M (2015) Vulnerability modeling of casinos in the United States: A case study of Philadelphia. Appl Geogr 63(2015):21-32. https://doi.org/10.1016/ j.apgeog.2015.05.015

Economopoulos A (2015) Examining the impact of casinos on economic development: A spatial analysis of the counties in the mid-Atlantic region. J Gambl Bus Econ 9(1):77-92. https://doi.org/10.5750/jgbe.v9i1.917
Engel RJ, Bechtold J, Kim Y, Mulvaney E (2013) Beating the odds: Preparing graduates to address gambling-related problems. J Soc Work Educ, 48(2), 321-335. https://doi.org/10.5175/JSWE.2012.201000128

Ferentzy P, Turner NE (2012) Morals, medicine, metaphors, and the history of the disease model of problem gambling. J Gambl Issue 27:1-28. https://doi.org/ 10.4309/jgi.2012.27.4

Gainsbury S, Wood R, Russell A, Hing N, Blaszczynski A (2012) A digital revolution: Comparison of demographic profiles, attitudes and gambling behavior of Internet and non-Internet gamblers. Comput Hum Behav 28(4):1388-1398. https://doi.org/10.1016/j.chb.2012.02.024

Gattis MN, Cunningham-Williams R (2011) Housing stability and problem gambling: Is there a relationship? J Soc Serv Res 37(5):490-499. https://doi.org/ 10.1080/01488376.2011.598716

Gerstein D, Murphy S, Toce M, Hoffman J, Palmer A, Chuchro L,... Hill MA (1999) Gambling impact and behavior study: Report to the National Gambling Impact Study Commission. Chicago, IL: National Opinion Research Center. http://www.norc.org/pdfs/publications/gibsfinalreportapril1999.pdf

Google Maps. (n.d.). [Home page]. https://google.maps.com

Goss E, Morse EA, Deskins J (2009) Have casinos contributed to rising bankruptcy rates? Int Adv Econ Res 15(4):456-469. https://doi.org/10.1007/s11294-0099234-7

Griswold MT, Nichols MW (2006) Social capital and casino gambling in U.S. communities. Soc Indicat Res 77(3):369-394. https://doi.org/10.1007/s11205004-6337-7

Hing N, Nisbet S (2010) A qualitative perspective on physical, social and cognitive accessibility to gambling. J Gambl Issue 24:101-120. https://doi.org/10.4309/ 2010.24.7

Hodgins DC, Petry NM (2016) The world of gambling: the National Gambling Experience series. Addiction 111:1516-1518. https://doi.org/10.1111/ add. 13445

Institute for American Values (2013) Why casinos matter: Thirty-one evidence-based propositions from the health and social sciences (A Report from the Council on Casinos). http://americanvalues.org/catalog/pdfs/why-casinos-matter.pdf

Kelly J, Catania F (2014) New York State casino development. Gaming Law Rev Econ 18(10):963-973. https://doi.org/10.1089/glre.2014.18107

Kerber C, Adelman-Mullally T, Kim M, Astroth KS (2015) The impact of disordered gambling among older adults. J Psychosoc Nurs 53(10):41-47. https://doi.org/10.3928/02793695-20150923-03

LaPlante DA, Shaffer HJ (2007) Understanding the influence of gambling opportunities: expanding exposure models to include adaptation. Am J Orthopsychiatr 77(4):616-623. https://doi.org/10.1037/0002-9432.77.4.616

Lim SH, Zhang L (2017) Does casino development have a positive effect on economic growth? Growth Change 48(3):409-434. 10.111/grow.12182

Martin F, Lichtenberg PA, Templin NT (2011) A longitudinal study: Casino gambling attitudes, motivations, and gambling patterns among urban elders. J Gambl Stud 272(2):287-297. https://doi.org/10.1007/s10899-010-9202-4

McEwan B (2018) Literature review, the. In: Allen M (ed.), The Sage encyclopedia of communication research methods. SAGE Publications, Inc. pp. 876-877

Mensah J (2019) Sustainable development: meaning, history, principles, pillars, and implications for human action: Literature review. Cogent Soc Sci 5(1):1-21. https://doi.org/10.1080/23311886.2019.1653531

Moore SM, Thomas AC, Kyrios M, Bates G, Meredyth D (2011) Gambling accessibility: a scale to measure gambler preferences. J Gambl Stud 27(1):129-143. https://doi.org/10.1007/s10899-010-9203-3

Nower L, Volberg RA, Caler KR (2017) The prevalence of online and land-based gambling in New Jersey. Report to the New Jersey Division of Gaming Enforcement. Center for Gambling Studies

Parmley S (2010, July 18) Table games debut at Parx, Harrah's Chester. The Philadelphia Inquirer. https://www.inquirer.com/philly/business/20100718_ Table_games_debut_at_Parx_Harrahs_Chester.html

Petry NM, Blanco C (2013) National gambling experiences in the United States: Will history repeat itself? Addiction 108(6):1032-1037. https://doi.org/ 10.1111/j.1360-0443.2012.03894.x

Philander KS (2019) Regionalimpacts of casino availability on gambling problems: evidence from the CanadianCommunity Health Survey. Tour Manag 71:173-178. https://doi.org/10.1016/j.tourman.2018.10.017

Prentice C, Zeng Z (2018) Fromgambling exposure to adaptation: implications for casino sustainability J Retail Consum Serv 41:31-36. https://doi.org/10.1016/ j.jretconser.2017.11.004

Rash CJ, Petry NM (2016) Gambling disorder in the DSM-5: Opportunities to improve diagnosis and treatment especially in substance use and homeless populations. Curr Addict Rep 3(3):249-253. https://doi.org/10.1007/s40429016-0112-0

Redmond W (2015) The provisioning of inequality. J Econ Issue 49(2):527-534. https://doi.org/10.1080/00213624.2015.1042799

Robitaille E, Herjean P (2008) An analysis of the accessibility of video lottery terminals: the case of Montréal. Int J Health Geogr 7(1):1-16. https://doi.org/ $10.1186 / 1476-072 \mathrm{X}-7-2$ 
Shaffer HJ (2005) From disabling to enabling the public interest: Natural transitions from gambling exposure to adaptation and self-regulation. Addiction 100(9):1227-1230. https://doi.org/10.1111/j.1360-0443.2005.01200.x

Shaffer HJ, LaBrie RA, LaPlante D (2004) Laying the foundation for quantifying regional exposure to social phenomena: considering the case of legalized gambling as a public health toxin. Psychol Addict Behav 18(1):40-48. https:// doi.org/10.1037/0893-164X.18.1.40

Shaffer HJ, Stanton MV, Nelson SE (2006) Trends in gambling studies research: Quantifying, categorizing, and describing citations. J Gambl Stud 22(4):427-442. https://doi.org/10.1007/s10899-006-9023-7

Stansbury KL, Beecher B, Schumacher M, Martin F, Clute MA (2015) Social service providers' perspectives on casino gambling in older adult clients. J Gambl Issue 30(30):57-72. https://doi.org/10.4309/jgi.2015.30.11

Stinchfield R, McCready J, Turner NE, Jimenez-Murcia S, Petry NM, Grant J, Winters KC (2016) Reliability, validity, and classification accuracy of the DSM-5 diagnosing criteria for gambling disorder and comparison to DSMIV. J Gambl Stud 32(3):905-922. https://doi.org/10.1007/s10899-015-9573-7

Tanner J, Mazmanian D (2016) Gambling attitudes and beliefs associated with problem gambling: the cohort effect of baby boomers. Int Gambl Stud 16(1):98-115. https://doi.org/10.1080/14459795.2016.1147591

Temcheff CE, Paskus TS, Potenza MN, Derevensky JL (2016) Which diagnostic criteria are most useful in discriminating between social gamblers and individuals with gambling problems? An examination of DSM-IV and DSM-5 criteria. J Gambl Stud 32(3):957-968. https://doi.org/10.1007/s10899-0159591-5

Thomas AC, Bates G, Moore S, Kyrios M, Meredyth D, Jessop G (2011) Gambling and the multidimensionality of accessibility: more than just proximity to venues. Int J Mental Health Addict 9(1):88-101. https://doi.org/10.1007/ s11469-009-9256-7

Thompson KM, McNeilly DP (2016) Populations at risk for a gambling disorder: Older adults. Curr Addict Rep 3(3):275-279. https://doi.org/10.1007/s40429016-0107-x

Tidwell M-C, Welte OJW, Barnes GM, Dayanim B (2015) Gambling modes and state gambling laws: changes from 1999 to 2011 and beyond. Gambl Law Rev Econ 19(1):13-26. https://doi.org/10.1089/glre.2014.1914

Tolchard B (2015) The impact of gambling on rural communities worldwide: a narrative literature review. J Rural Mental Health 39(2):90-107. https:// doi.org/10.1037/rmh0000030

Tong HHY, Chim D (2013) The relationship between casino proximity and problem gambling. Asian J Gambl Issue Public Health 3(2):1-17. https://doi.org/ 10.1186/2195-3007-3-2

Tse S, Hing SI, Wang CW, Cunningham-Williams RW (2012) Gambling behavior and problems among older adults: a systematic review of empirical studies. J Gerontol Ser B: Psychol Sci Soc Sci 67(5):639-652. https://doi.org/10.1093/ geronb/gbs068

Turner NE, van der Maas M, McCready J, Hamilton HA, Schrans T, Ialomiteanu A, Mann RE (2018) Gambling behaviours and problem gambling among older adults who patronize Ontario casinos or racinos. J Gambl Issue 39(2018):85-111. https://doi.org/10.4309/jgi.2018.39.4

United States Department of Agriculture Economic Research Center (n.d.). Rural definitions: data documentation and methods. Retrieved July 1, 2019, from https://www.ers.usda.gov/data-products/rural-definitions/datadocumentation-and-methods.aspx

Vasiliadis SD, Jackson AC, Christensen D, Francis K (2013) Physical accessibility of gaming opportunity and its relationship to gaming involvement and problem gambling: a systematic review. J Gambl Issue 28(2013):1-46. https://doi.org/ 10.4309/jgi.2013.28.2

Walker DM, Jackson JD (2011) The effect of legalization gambling on state government revenue. Contemp Econ Policy 29(1):101-114. https://doi.org/ $10.1111 / j .1465-7287.2010 .00198 . x$

Walker DM, Sobel RS (2016) Social and economic impacts of gambling. Curr Addict Rep 3(3):293-298. https://doi.org/10.1007/s40429-016-0109-8

Welte JW, Barnes GM, Tidwell M-CO, Hoffman JH (2009) Legal gambling availability and problem gambling among adolescent and young adults. Int Gambl Stud 9(2):89-99. https://doi.org/10.1080/14459790902754996
Welte JW, Barnes GM, Tidwell MO, Hoffman JH, Wieczorek WF (2016a) The relationship between distance from gambling venues and gambling participation and problem gambling among U.S. adults. J Gambl Stud 32(2):1-9. https://doi.org/10.1007/s10899-015-9831-5

Welte JW, Barnes GM, Tidwell MO, Hoffman JH, Wieczorek WF (2016b) The relationship between the number of types of legal gambling and the rates of gambling behaviors and problems across the U.S. states. J Gambl Stud 32(2):379-390. https://doi.org/10.1007/s10899-015-9551-0

Welte JW, Barnes GM, Tidwell M-CO, Wieczorek WF (2017) Predictors of problem gambling in the U.S. J Gambl Stud 33(2):327-342. https://doi.org/ 10.1007/s10899-016-9639-1

Welte JW, Wieczorek WF, Barnes GM, Tidwell M-C, Hoffman JH (2004) The relationship of ecological and geographic factors to gambling behavior and pathology. J Gambl Stud 20(4):405-423. https://doi.org/10.1007/s10899-004$4582-\mathrm{y}$

Wenz M (2014) Valuing casinos as a local amenity. Growth Change 45(1):136-158. https://doi.org/10.1111/grow.12036

Xouridas S, Jasny J, Becker T (2016) An ecological approach to electronic gaming machines and socio-economic deprivation in Germany. J Gambl Issue 33(2016):82-102. https://doi.org/10.4309/jgi.2016.33.6

\section{Acknowledgements}

The author is thankful to Georgia Rose and Margaret Francis for their useful suggestions.

\section{Competing interests}

The author declares no competing interests.

\section{Ethical approval}

The author confirms that all research was performed in accordance with relevant guidelines and regulations. Ethical approval was obtained from the Institutional Review Board of Capella University.

\section{Informed consent}

This article does not contain any studies with human participants performed by the author.

\section{Additional information}

Correspondence and requests for materials should be addressed to Paulette J. O'Gilvie.

Reprints and permission information is available at http://www.nature.com/reprints

Publisher's note Springer Nature remains neutral with regard to jurisdictional claims in published maps and institutional affiliations.

Open Access This article is licensed under a Creative Commons Attribution 4.0 International License, which permits use, sharing, adaptation, distribution and reproduction in any medium or format, as long as you give appropriate credit to the original author(s) and the source, provide a link to the Creative Commons license, and indicate if changes were made. The images or other third party material in this article are included in the article's Creative Commons license, unless indicated otherwise in a credit line to the material. If material is not included in the article's Creative Commons license and your intended use is not permitted by statutory regulation or exceeds the permitted use, you will need to obtain permission directly from the copyright holder. To view a copy of this license, visit http://creativecommons.org/ licenses/by/4.0\%

(C) The Author(s) 2022 